\title{
LSD1 sustains estrogen-driven endometrial carcinoma cell proliferation through the PI3K/AKT pathway via di-demethylating H3K9 of cyclin D1
}

\author{
CHUNQIN CHEN $^{1 *}$, YANAN WANG ${ }^{1 *}$, SHIYU WANG ${ }^{1}$, YUAN LIU $^{1}$, JIAWEN ZHANG $^{2}$, \\ YUYAO XU $^{1}$, ZHENBO ZHANG ${ }^{1}$, WEI BAO ${ }^{1}$ and SUFANG WU ${ }^{1}$ \\ ${ }^{1}$ Department of Obstetrics and Gynecology, Shanghai General Hospital, Shanghai Jiao Tong University \\ School of Medicine; ${ }^{2}$ Department of Obstetrics and Gynecology, Shanghai Tenth People's Hospital, \\ Shanghai Tongji University, Shanghai, P.R. China
}

Received October 25, 2016; Accepted December 19, 2016

DOI: 10.3892/ijo.2017.3849

\begin{abstract}
A recent study reported that histone lysine specific demethylase 1 (LSD1, KDM1A) is overexpressed in endometrioid endometrial carcinoma (EEC) and associated with tumor progression as well as poor prognosis. However, the physiological function and mechanism of LSD1 in endometrial cancer (EC) remains largely unknown. In this study, we demonstrate that $\beta$-estradiol (E2) treatment increased LSD1 expression via the GPR30/PI3K/AKT pathway in endometrial cancer cells. Both siGPR30 and the PI3K inhibitor LY294002 block this effect. RNAi-mediated silencing of LSD1 abolished estrogen-driven endometrial cancer cell (ECC) proliferation, and induced G1 cell arrest and apoptosis. Mechanistically, we find that LSD1 silencing results in PI3K/AKT signal inactivation, but without the elevation of PTEN expression as expected. This is because the inhibition of LSD1 induces dimethylation of lysine 9 on histone $\mathrm{H} 3(\mathrm{H} 3 \mathrm{~K} 9 \mathrm{~m} 2)$ accumulation at the
\end{abstract}

Correspondence to: Dr Sufang Wu or Dr Wei Bao, Department of Obstetrics and Gynecology, Shanghai General Hospital, Shanghai Jiao Tong University School of Medicine, 650 Xinsongjiang Road, Songjiang, Shanghai 201600, P.R. China

E-mail:wsf_sfphsh@163.com

E-mail: forever_chipper@hotmail.com

*Contributed equally

Abbreviations: EC, endometrial cancer; EEC, endometrioid endometrial carcinoma; LSD1, histone lysine specific demethylase 1; ATCC, American Type Culture Collection; Bcl-2, B cell leukemia lymphoma-2; $\mathrm{H} 3 \mathrm{~K} 4 \mathrm{~m} 2$, dimethylation of histone $\mathrm{H} 3$ lysine 4; H3K9m2, dimethylation of histone H3 lysine 9; E2, 17 $\beta$-estradiol; HSS, histological staining scores; EtOH, ethanol; P21, cyclindependent kinase inhibitor 21; caspase-3, cysteinyl aspartate-specific proteinase-3; ChIP, chromatin immunoprecipitation

Key words: LSD1, cyclin D1, endometrial cancer, PI3K/AKT, PTEN, estrogen promoter region of cyclin D1. Interfering with cyclin D1 leads to PI3K/AKT signal suppression. Re-overexpression of cyclin D1 in LSD1-knockdown ECCs reverses the LSD1 inhibitory action. Our finding connects estrogen signaling with epigenetic regulation in EEC and provides novel experimental support for LSD1 as a potential target for endometrial cancer therapeutics.

\section{Introduction}

Endometrial cancer (EC) is the most commonly diagnosed gynecological cancer. The National Cancer Institute estimates $\sim 60,050$ new cancer cases and 10,470 deaths in the United States in 2016 (1). Endometrial cancer consists of two types: estrogen dependent (type I) and non-estrogen dependent (type II) (2); type I accounts for $>70-80 \%$ of all endometrial cancer types $(3,4)$. In recent years, estrogen has been considered to be the classic etiologic factor for type I endometrial cancer tumorigenesis, which is directly related to PTEN loss or mutation, PI3K/AKT, MAPK/ERK and Wnt/B-catenin pathway activation $(3,5-8)$. Although many studies have been conducted, the modulation mechanisms of estrogen-driven endometrioid endometrial carcinoma remain poorly understood.

Histone lysine methylation is a crucial regulator of transcription, and its dysregulation is associated with oncogenesis (9-11). As the first demethylase detected by Shi and coworkers in 2004 (11), histone lysine specific demethylase 1 (LSD1, KDM1A) is an amine oxidase that functions as a histone demethylase that specifically mono- or di-demethylates histone 3 lysine 4 (H3K4) or lysine 9 (H3K9) and a transcriptional co-repressor included in the REST/Co-Rest complex $(12,13)$. LSD1 expression is elevated in many human malignancies, such as breast cancer (14), prostate cancer (15), pancreatic cancer (16), ovarian cancer (17), small cell lung carcinoma (18) and leukemia (19). Theisen et al (20) demonstrated that the LSD1 inhibitor HCI2509 inhibited the proliferation of type II endometrial carcinoma cell lines by disturbing cell cycle progression and inducing apoptotic cell death. Recently, Liu et al (21) reported that LSD1 was 
overexpressed in endometrioid endometrial adenocarcinoma (EEA) and is related to overall survival (OS) and disease-free survival (DFS) of EEA patients. However, the underlying biological function and molecular mechanism of LSD1 in EEA remains largely unknown.

Increasing evidence suggested that LSD1 play a major role in hormone-dependent gene expression and proliferation processes of cell growth and is related to transcriptional regulation of estrogen- or androgen-responsive genes $(22,23)$. Estrogen stimulation increases LSD1 level in the EREs of pS2 and PR genes in breast cancer (24). It had been demonstated that LSD1 can be recruited by nuclear receptor TLX to the promoter of PTEN to downregulate it $(25,26)$, which is a negative regulator of the PI3K/AKT pathway (27). Inactivating PI3K/AKT signaling could block EGF-induced expression of LSD1 in ovarian cancer (28). These findings imply that LSD1 may be involved in PI3K/AKT signaling and might play a critical role in EEC occurrence and development. As expected, this study found remarkable upregulation of LSD1 after E2 treatment in endometrial cancer. In addition, we found that LSD1/cyclin D1/PI3K/AKT established a feedback loop in the regulation of the proliferation of endometrial cancer Ishikawa and HEC-1-A cells. Our findings provide a novel insight into the mechanism of LSD1 in carcinogenesis.

\section{Materials and methods}

Ethics statement. Our study was permitted by the Ethics Committee of both Shanghai General Hospital (Shanghai, China) and Shanghai Jiao Tong University School of Medicine, and written consent was obtained from all participants.

Cell lines and cell culture. Endometrial cancer cell lines Ishikawa, RL-95-2, HEC-1-A, and HEC-1-B were maintained in our laboratory and were initially obtained from the ATCC. Cells were cultured in 1:1 DMEM/F12 (Gibco, Auckland, New Zealand) with 5\% penicillin-streptomycin and $10 \%$ fetal bovine serum (Gibco, Gaithersburg, MD, USA).

Gene silence and plasmid transfection. Ishikawa and HEC-1-A cells were seeded in a 6-well plate. The LSD1, cyclin D1 and GPR30 small interfering RNAs (siRNA) were designed and synthesized by RiboBio Inc. (RiboBio, Guangzhou, China) to knock down the LSD1, cyclin D1, GPR30 genes at a $50 \mathrm{nM}$ concentration, respectively. The sequences are as follows: siLSD1: 5'-CCACGAGUCAAACCUUUAUTT-3' (F), 5'-AUA AAGGUUUGACUCGUGGTT-3' (R); siGPR30: 5'-GCUGU ACAUUGAGCAGAAATT-3' (F), 5'-UUUCUGCUCAAUG UACAGCTT-3' (R); sicyclin D1: 5'-UGGAAUAGCUUCUG GAAUUdTdT-3' (F), 5'-dTdAACCUUAUCGAAGACCU UAA-3' (R); siCtrl served as a transfection control: 5'-UUC UCCGAACGUGUCACGUTT-3' (F), 5'-ACGUGACACGU UCGGAGAATT-3' (R). The cyclin D1 plasmid was purchased from the Public Protein/Plasmid Library (Genecopoeia, Nanjing, China).

Hormone and drug treatments. To investigate the effects of $\beta$-estradiol on LSD1 expression, Ishikawa and HEC-1-A cells were treated with different concentrations of E2 (Sigma-Aldrich, St. Louis, MO, USA) for $24 \mathrm{~h}$, followed by western blotting to determine LSD1 protein changes. Subsequently, cells were treated with E2 $(1 \mathrm{nM})$ for various times to examine the effect of time. To further analyze whether the PI3K/AKT pathway is essential for E2 induced LSD1 accumulation, LY294002 (10 mM, Sigma-Aldrich), a specific inhibitor for PI3K/AKT, was used to pre-treat cells for $1 \mathrm{~h}$ prior to E2 treatment for $48 \mathrm{~h}$, and the changes in relevant protein levels were examined by western blotting. Cells were transfected with two sequences of siLSD1 or siControl prior to ethanol or E2 $(1 \mathrm{nM})$ treatment for another $48 \mathrm{~h}$ to investigate their roles in cell proliferation, cell cycle and cell apoptosis.

Immunoblotting and antibodies. Whole cells were lysed in lysis buffer on ice. Then, total protein was loaded onto SDS-PAGE and transferred onto polyvinylidene fluoride membranes (PVDF). Then, the membranes were blocked with 5\% BSA (Roche, Mannheim, Germany) for $1 \mathrm{~h}$ prior to incubation overnight with primary antibodies at $4^{\circ} \mathrm{C}$ on a shaking table. Antibodies against human LSD1, PTEN, AKT, phosphorylated AKT (Ser473), ERK, phosphorylated ERK (Thr202/Tyr204), and cleaved caspase-3 (1:1,000 diluted in 5\% BSA) were purchased from Cell Signaling Technology Inc. Antibodies against human cyclin D1, P21, and histone $\mathrm{H} 3$ (1:1,000 diluted in 5\% BSA) were purchased from Abcam Inc. Antibodies against human $\beta$-actin and GAPDH (1:2,000 diluted in 5\% BSA) were purchased from Abzoom Biolabs. Inc. Immunodetection was achieved after incubation with the secondary antibodies (1:5,000, West Grove, PA, USA) in BSA for $1 \mathrm{~h}$ at room temperature. ECL chemiluminescent reagents were used to reveal the target signal on the membranes.

Tissue samples and immunohistochemistry. Tissues samples were obtained from 48 endometrial cancer patients and 25 patients with normal endometrium who underwent hysterectomy operation at Shanghai General Hospital from 2008 to 2015. IHC analyses of LSD1 protein levels were implemented as previously described (29). The sections were incubated with rabbit anti-human LSD1 and cyclin D1 antibody (diluted to 1:500; CST). Expression of LSD1 protein was assessed by the following method: the index of LSD1 expression was calculated as the intensity of the staining (0-3) $x$ the percentage of positively stained cells (0-3). The final histological staining scores (HSS) were divided into two groups as followed: low-expression group (HSS <4) and high-expression group (HSS $\geq 4)$. In 48 endometrial tissues, the expression of LSD1 and the cyclin D1 level were analyzed by Pearson correlation test.

CCK-8 assay. Cells were plated into 96 -well plates (2,000 cells per well), and incubated for $24 \mathrm{~h}$. CCK-8 solution (Signalway Antibody Co., Ltd. MD, USA) was added for another $2 \mathrm{~h}$ and then incubated for 12, 24 and $48 \mathrm{~h}$. Then, the absorbance was measured at $450 \mathrm{nM}$ with a GENios multifunction reader (Tecan, Zurich, Switzerland).

Clonogenic assays. Cells were seeded in capsules at a density of 1,000 cells/plate after treatment. After 3 weeks of 
Table I. Association between clinical characteristics of LSD1 expression in endometrial cancer patients.

\begin{tabular}{|c|c|c|c|c|c|}
\hline \multirow[b]{2}{*}{ Parameters } & \multirow[b]{2}{*}{$\mathrm{N}=48$} & \multicolumn{3}{|c|}{ LSD1 expression } & \multirow[b]{2}{*}{ P-value } \\
\hline & & \multicolumn{2}{|c|}{$\begin{array}{c}\text { Low }(\mathrm{N}=15) \\
(\%)\end{array}$} & $\begin{array}{c}\operatorname{High}(\mathrm{N}=33) \\
(\%)\end{array}$ & \\
\hline Age & & & & & 0.809 \\
\hline$<50$ & 18 & 6 & $(40.0)$ & $12(36.3)$ & \\
\hline$\geq 50$ & & & & & \\
\hline FIGO stage & 30 & 9 & $(60.0)$ & $21(63.6)$ & \\
\hline Stage I-II & 26 & 12 & $(80.0)$ & $14(42.4)$ & 0.015 \\
\hline Stage III-IV & 22 & 3 & $(20.0)$ & $19(57.6)$ & \\
\hline \multicolumn{6}{|l|}{ Grade } \\
\hline G1-G2 & 31 & 13 & $(86.7)$ & $18(54.5)$ & 0.031 \\
\hline G3 & 17 & 2 & $(13.3)$ & $15(45.5)$ & \\
\hline \multicolumn{6}{|l|}{$\begin{array}{l}\text { Nodal } \\
\text { metastasis }\end{array}$} \\
\hline Positive & 6 & 0 & $(0.0)$ & $6(18.2)$ & 0.078 \\
\hline Negative & 42 & & (100.0) & $27(81.8)$ & \\
\hline \multicolumn{6}{|l|}{ Invasion } \\
\hline$<1 / 2$ & 31 & 10 & $(66.7)$ & $21(63.6)$ & 0.839 \\
\hline$\geq 1 / 2$ & 17 & 5 & $(33.3)$ & $12(36.4)$ & \\
\hline
\end{tabular}

P-values are statistically significant at the level of 0.05 .

incubation, colonies of $>50$ cells were produced, which were photographed.

Cell apoptosis and cell cycle analysis. Ishikawa and HEC-1-A cells were cultured, treated with or without $1 \mathrm{nM}$ estradiol and LSD1 siRNA, and harvested at the indicated times. To analyze cell apoptosis, cells were collected and washed with ice-cold PBS three times $24 \mathrm{~h}$ after transfection. Cells were incubated with PE Annexin V and propidium iodide (PI) according to the PE Annexin V Apoptosis Detection Kit I (BD Pharmingen, CA, USA) protocol and analyzed using a BD FACSCalibur. For cell cycle analysis, cells were fixed in ice-cold ethanol (75\%) and incubated at $4^{\circ} \mathrm{C}$ overnight. Then, the cells were stained with $10 \mu 1$ of PI $(10 \mathrm{mg} / \mathrm{ml})$ in the presence of $10 \mu \mathrm{g} / \mathrm{ml}$ RNase A and analyzed using a BD Biosciences FACS Aria flow cytometer.

Chromatin immunoprecipitation. Cells were fixed in formaldehyde, lysed, and sonicated to break the chromatin into 500-bp fragments. A ChIP-grade antibody against H3K9me2 was used to precipitate chromatin fragments from cell extracts. Isotype-specific IgG was used as a negative control. We used real-time quantitative PCR to amplify the DNA fragments in the antibody precipitated DNA and the unprecipitated input DNA was used to calculate the percentage. The PCR primer set used for amplification of the precipitated fragments was F, ACGAAGTTCCTAGTCGAGAT; R, CGCGTGCGCCCTG GCCCAG.
Statistical analysis. All values are expressed as the mean \pm standard error. The results were analyzed by two-way analysis of variance or t-test as appropriate with SAS Release 8.02 (SAS Institute Inc., Cary, NC, USA) or GraphPad Prism v5.0 (GraphPad, San Diego, CA, USA). P $<0.05$ was considered statistically significant. All experiments were performed in triplicate.

\section{Results}

LSD1 is highly expressed in human endometrial cancer tissues and cell lines. We performed immunohistochemistry (IHC) in normal endometrium and endometrial cancer tissues. Compared with normal endometrial tissues, endometrial carcinoma tissues had more positive IHC staining of LSD1 in the nucleus (Fig. 1A), and IHC scoring confirmed the significantly higher LSD1 protein expression in carcinoma tissues (Fig. 1B). LSD1 expression was showed a positive result with the FIGO stage $(\mathrm{P}=0.015)$ and tumor grade $(\mathrm{P}=0.031)$, but no relationship was observed between LSD1 expression and the age, nodal metastasis or the depth of tumor myometrial invasion (Table I). Furthermore, we examined the expression of LSD1 in several human endometrial cancer cell lines, with protein from primary cultured normal endometrial cells (NE), and endometrial stromal cells (ESC) as controls (Fig. 1C). The results suggested that LSD1 expression is high in these human endometrial cancer cell lines, with the highest levels observed in Ishikawa cells. We chose Ishikawa and HEC-1-A cells in the following investigation.

E2 induces LSD1 expression through the GPR30/PI3K/AKT signal pathway. 17ß-estradiol (E2) was shown to increase the protein level of LSD1 in a dose-dependent manner, with the greatest effect at a dose of $1 \mathrm{nM}$ in both Ishikawa and HEC-1-A cells (Fig. 2A). Moreover, we found that E2 $(1 \mathrm{nM})$ markedly elevated LSD1 protein expression in a time-dependent manner (Fig. 2B). To further investigate the underlying molecular mechanisms, we treated Ishikawa and HEC-1-A cells with the membrane-associated estrogen receptor, GPR30 siRNA, and LY294002, a specific inhibitor for PI3K/AKT pathway for $1 \mathrm{~h}$ prior to E2 $(1 \mathrm{nM})$ treatment for $48 \mathrm{~h}$. E2-induced activation of LSD1 was attenuated by siGPR30 or LY294002 treatment (Fig. 2C). These data indicate that E2 enhances LSD1 expression through the activation of the GPR30/PI3K/AKT signaling pathways.

Upregulation of LSD1 is required for estrogen-induced ECC proliferation. Since the observation of significant accumulation of LSD1 in endometrial carcinoma, we speculated that LSD1 might play a crucial role in estrogen-driven cellular proliferation. To confirm this hypothesis, we first explored the biological function of LSD1 in endometrial cancer cells, we knocked down LSD1 prior to ethanol (EtOH) or E2 $(1 \mathrm{nM})$ treatment in both Ishikawa and HEC-1-A cells. A CCK-8 assay revealed that cellular proliferation was decreased in LSD1-depleted cells at 24 and $48 \mathrm{~h}$ compared to negative control (siCtrl) transfected cells. Estrogen addition greatly promoted cell growth post E2 treatment for $24 \mathrm{~h}$, while the knockdown of LSD1 significantly abolished E2-enhanced proliferation (Fig. 3A). In addition, the attenuation of LSD1 
A

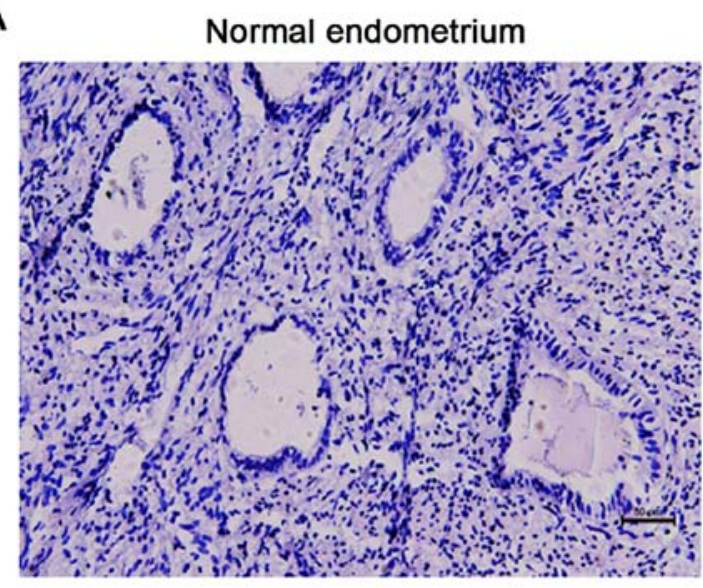

B

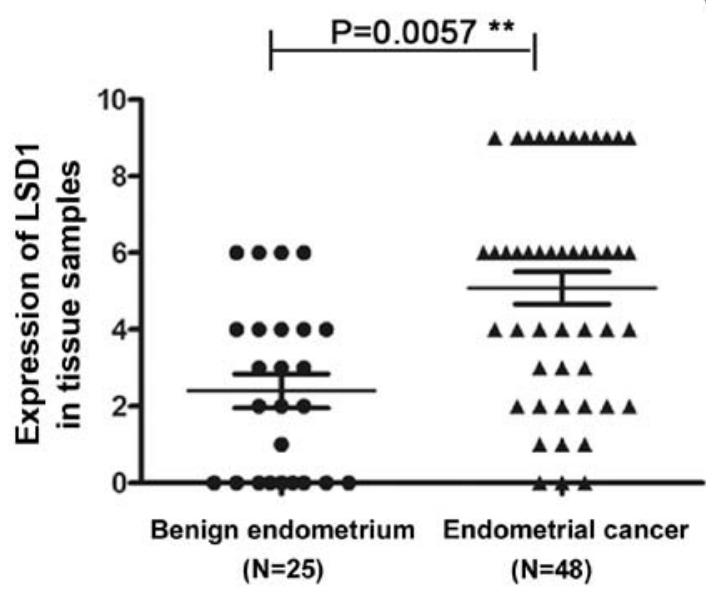

Endometrial carcinoma

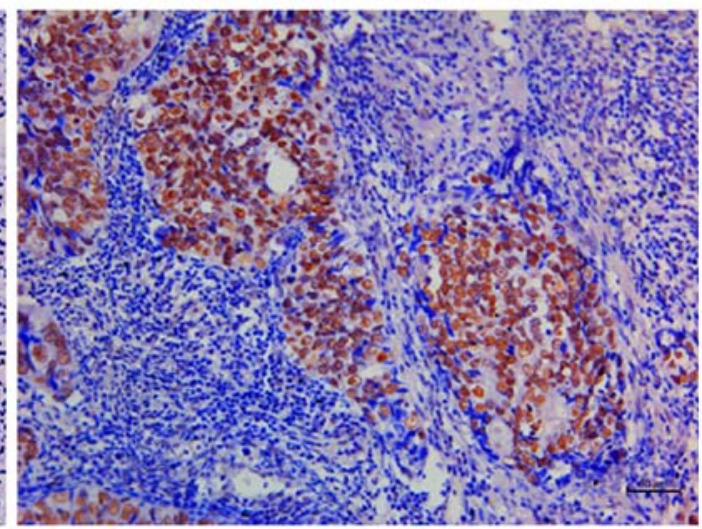

C
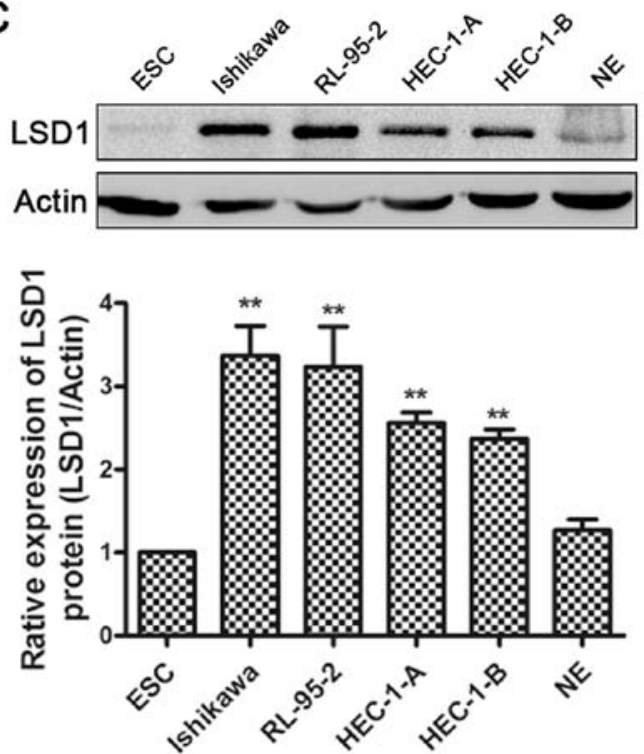

Figure 1.LSD1 expressions in clinical samples and cell lines. (A) Immunohistochemical staining of LSD1 protein in clinical endometrial tissues. Magnification, $\mathrm{x} 200$. (B) Comparison of LSD1 protein expression between normal endometrium and endometrial cancer tissues. ${ }^{* *} \mathrm{P}<0.01$. (C) Immunoblot analysis of LSD1 expression in the immortalized ESC line, primary cultured normal endometrial cells and endometrial cancer cell lines. ${ }^{* *} \mathrm{P}<0.01$, compared with ESC.

caused significant inhibition of cell growth compared to siCtrl cells as measured by clonogenic assays (Fig. 3B). Because cell cycle and cell apoptosis are closely associated with cell growth, we performed cell apoptosis detection and flow cytometric analysis of the cell cycle. As a result, we found that siLSD1 treatment led to acute arrest in the G0/G1 phase (Fig. 3C) and induction of apoptosis (Fig. 3D) under both EtOH and E2 treatments.

LSDI establishes a feedback loop in PI3K/AKT/cyclin D1 axis by demethylating $\mathrm{H} 3 \mathrm{~K} 9 \mathrm{me} 2$ at the promoter of cyclin D1. To further assess the molecular mechanisms responsible for the growth inhibition function of LSD1 in estrogen-driven endometrial cancer cells, given that PI3K/ AKT and MAPK-ERK signaling pathways are critical in type I endometrial cancer development and that hyperactivation of the two pathways contributed to enhanced tumorigenic proliferation, we examined PI3K/AKT, ERK1/2 using western blotting in treated Ishikawa and HEC-1-A cells. The levels of phospho-AKT were notably reduced, as expected, by LSD1 silencing in the EtOH and E2 treated groups, while phospho-ERK expression had little change (Fig. 4A). This implied that LSD1 could promote ECC proliferation via the activation of PI3K/AKT signaling but not the MAPK-ERK pathway. Interestingly, no PTEN upregulation was found in both Ishikawa cells (PTEN) ${ }^{-}$or HEC-1-A cells $\left(\mathrm{PTEN}^{+}\right)$ (30) when LSD1 was knocked down, which suggested LSD1 affects PI3K/AKT signaling via other pathways rather than regulating PTEN. We then detected PI3K/AKT downstream cell cycle and apoptosis related proteins. The attenuation of LSD1 by siRNA caused downregulation of cyclin D1, but did not change Bcl-2 (data not shown) compared to siCtrl groups with EtOH treatment. In contrast, P21 (cyclin-dependent kinase inhibitor 21) and cleaved caspase-3 were upregulated. E2 stimulated the expression of phospho-AKT, phosphoERK, cyclin D1, Bcl-2, and weakened the expression of P21 and cleaved caspase-3. When LSD1 was silenced, we found phospho-AKT, cyclin D1 and Bcl-2 were ablated. Moreover, P21 and cleaved caspase-3 were upregulated (Fig. 4B). Because there was a dramatic change in cyclin D1 expression 
A

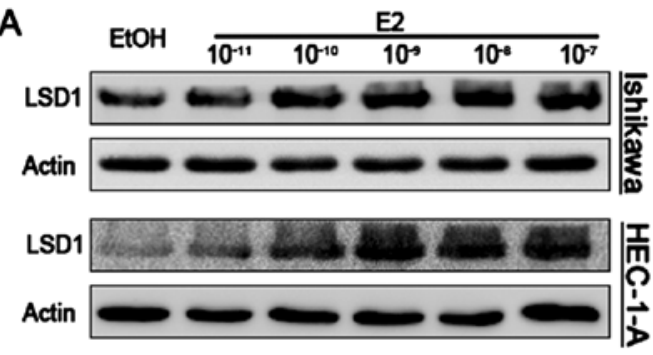

B

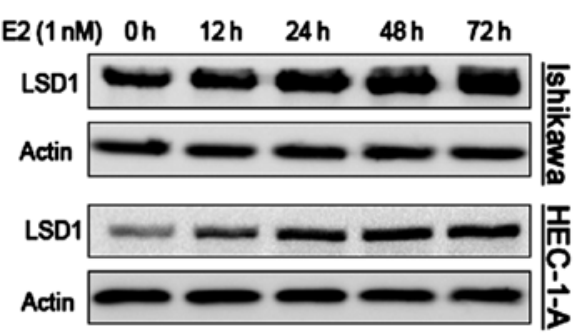

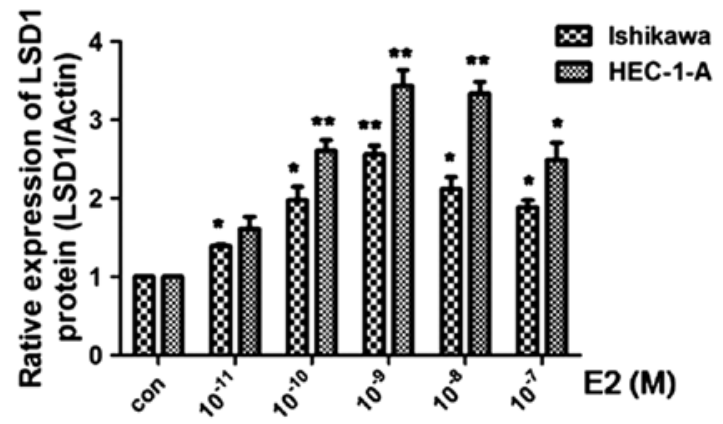

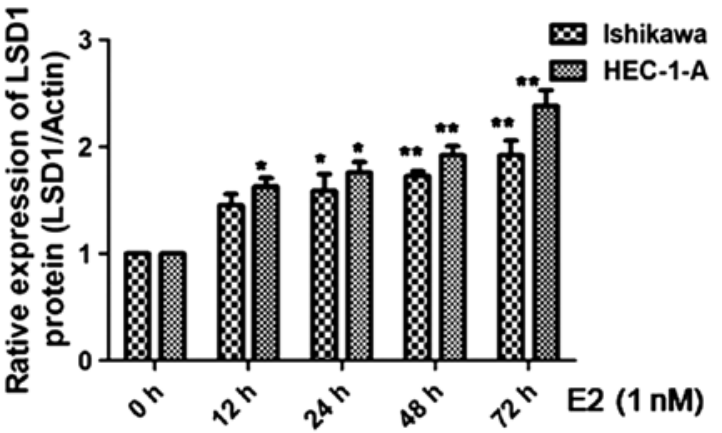

C

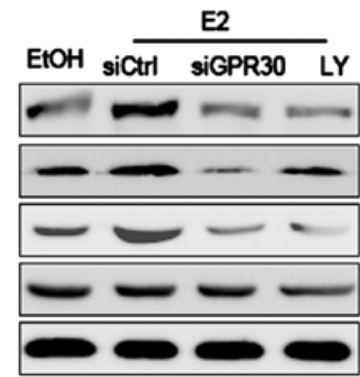

Ishikawa

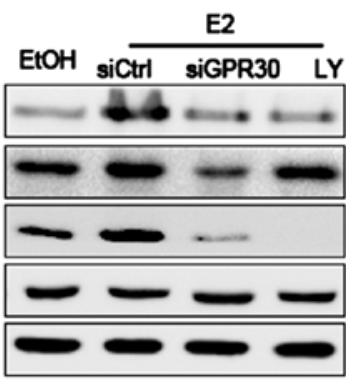

HEC-1-A

\section{LSD1 \\ GPR30 \\ PAKT \\ AKT \\ GAPDH}
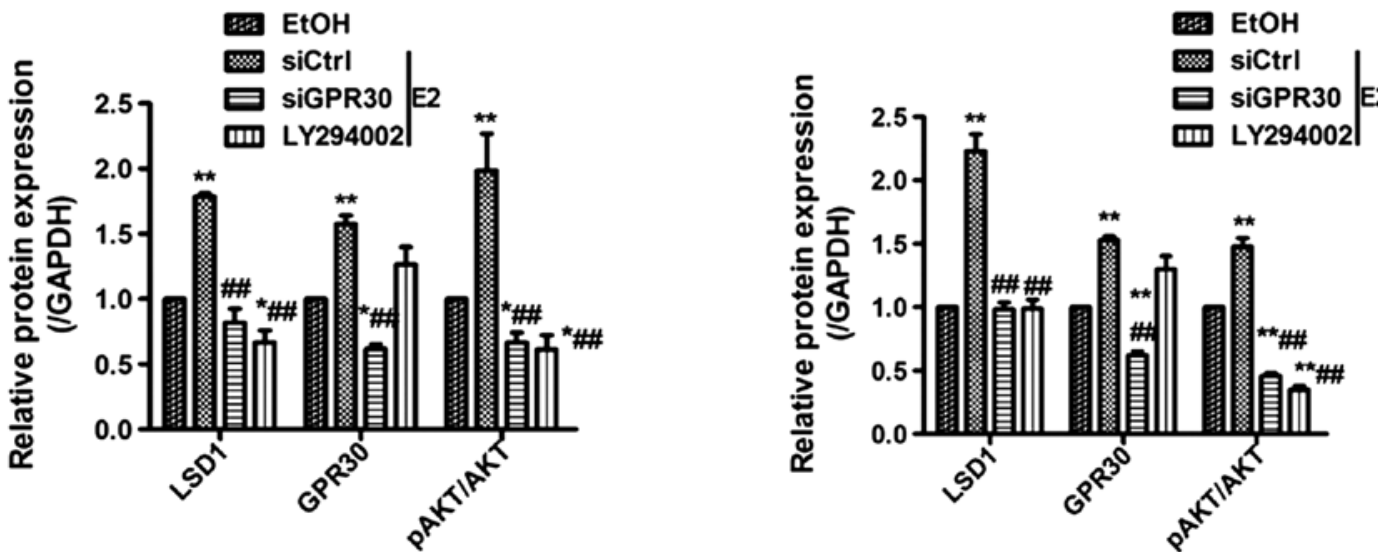

Figure 2. E2 treatment upregulates LSD1 level via activating the GPR30/PI3K/AKT signal. (A) Protein level of LSD1 in Ishikawa and HEC-1-A cells in an E2 dose-dependent manner. ${ }^{*} \mathrm{P}<0.05,{ }^{* *} \mathrm{P}<0.01$ compared with controls. (B) Protein level of LSD1 in an E2 time-dependent manner in Ishikawa and HEC-1-A cells. ${ }^{*} \mathrm{P}<0.05,{ }^{* * *} \mathrm{P}<0.01$ (C) siGPR30 and PI3K/AKT inhibitor LY294002 addition blocked the E2-induced upregulation of LSD1. "P $<0.05$, ${ }^{* * *} \mathrm{P}<0.01$ compared with EtOH groups. ${ }^{\#} \mathrm{P}<0.05,{ }^{\# \#} \mathrm{P}<0.01$ compared with the siControl groups treated with E2.

after treatment with LSD1-specific RNAi, and a recent study reported that cyclin D1 interference inhibits PI3K/AKT level in colon cancer cells (31), we speculated cyclin D1 may play a similar role in ECCs. To verify this, we interfered with cyclin D1 using siRNA, and a western blotting confirmed that the phosphorylation levels of $\mathrm{p}$-AKT and $\mathrm{Bcl}-2$ were reduced as expected (Fig. 4C). Cleaved caspase-3 expression was elevated. When we re-overexpressed cyclin D1 in Ishikawa and HEC-1-A cells, levels of p-AKT, Bcl-2 and cleaved caspase- 3 were restored. As expected, CCK- 8 assays illustrated that the overexpression of cyclin D1 could counteract the LSD1 effects on cellular proliferation inhibition in 
A
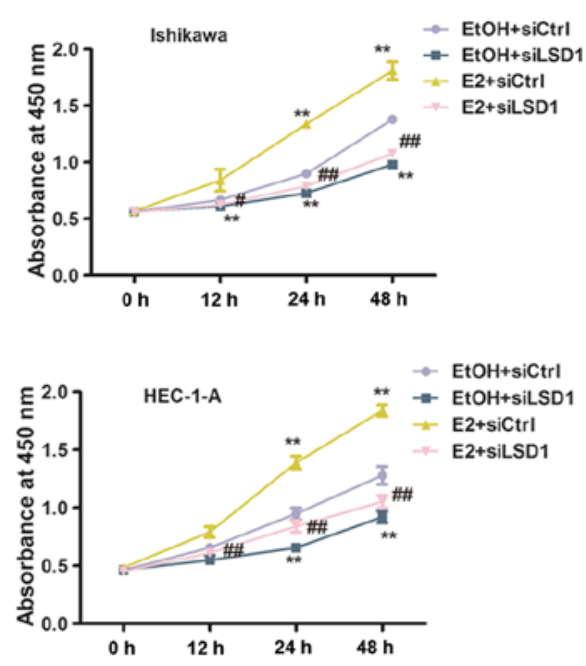

B

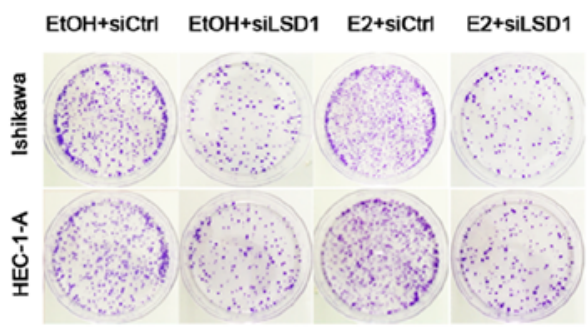

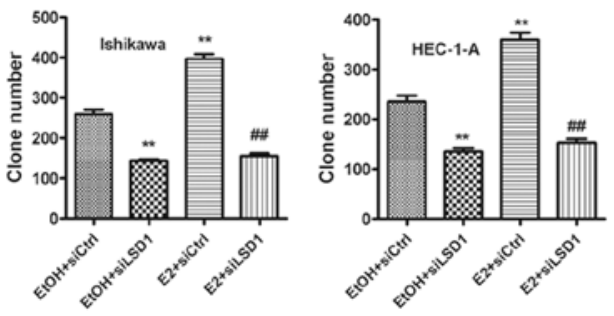
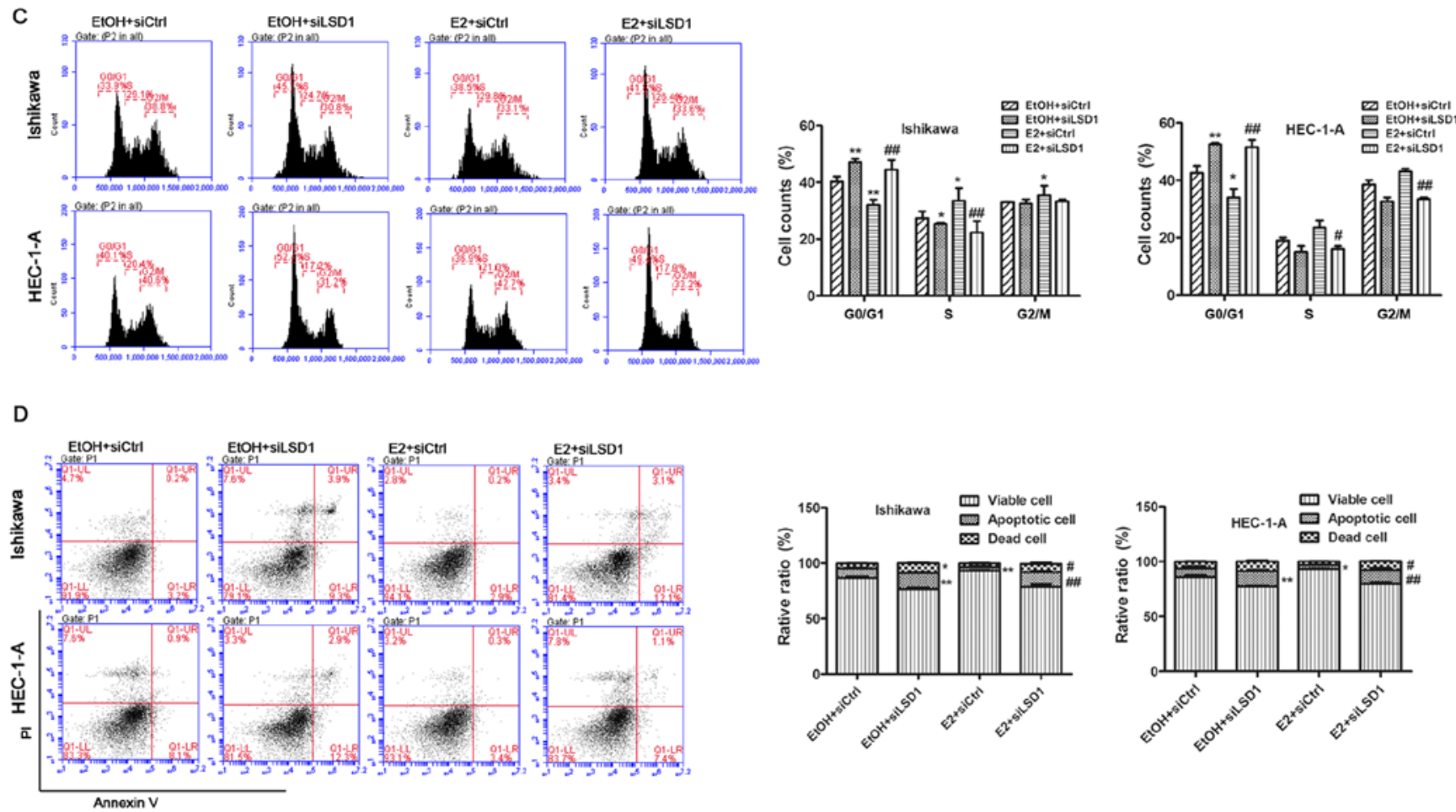

Figure 3. LSD1 is required for the E2-driven endometrial cancer cell growth. Knockdown of LSD1 suppressed tumor growth as assessed by a CCK-8 assay (A) and a colony-forming assay (B). siLSD1 led to cell cycle G1/S arrest (C) and induced apoptosis in ECCs (D). ${ }^{*} \mathrm{P}<0.05,{ }^{* *} \mathrm{P}<0.01$ compared with siControl groups. ${ }^{\text {"} \mathrm{P}}<0.05,{ }^{\# \#} \mathrm{P}<0.01$ compared with the siControl groups treated with $\mathrm{E} 2$.

ECCs while LY294002 addition led to extreme proliferation inhibition in ECCs (Fig. 4D). An increase in total H3K9me2 was observed by western blotting when LSD1 was silenced in E2 treated HEC-1-A cells. We did not detect obvious H3K4me2 changes (Fig. 4E). To test whether LSD1 contributes to the direct increases of cyclin D1 gene expression by demethylation in EEC, we performed chromatin immunoprecipitation (ChIP) analyses, H3K9 dimethylation levels were markedly increased compared to siControl treated HEC-1-A cells (Fig. 4F).

LSD1 is positively correlated with cyclinD1 in EEC tissues. Furthermore, we confirmed this phenomenon in endometrial cancer tissues. We detected LSD1 and cyclin D1 using IHC staining in EEC tissue specimens (Fig. 5A). Consistently, correlation analysis showed that the expression of LSD1 was positively correlated with the level of cyclin $\mathrm{D} 1\left(\mathrm{R}^{2}=0.521\right.$, $\mathrm{P}<0.001$, Fig. 5B).

\section{Discussion}

Modification of histone is not only associated with the chromosome remodeling and function, but also important in determining the cell fate, cell growth, as well as carcinogenesis (32). Lysine-specific demethylase 1, the first found histone demethylase, has been implicated in the process of tumor progression at various stages. Recently, it has been reported that LSD1 is involved in endometrioid endometrial carcinoma, 
A
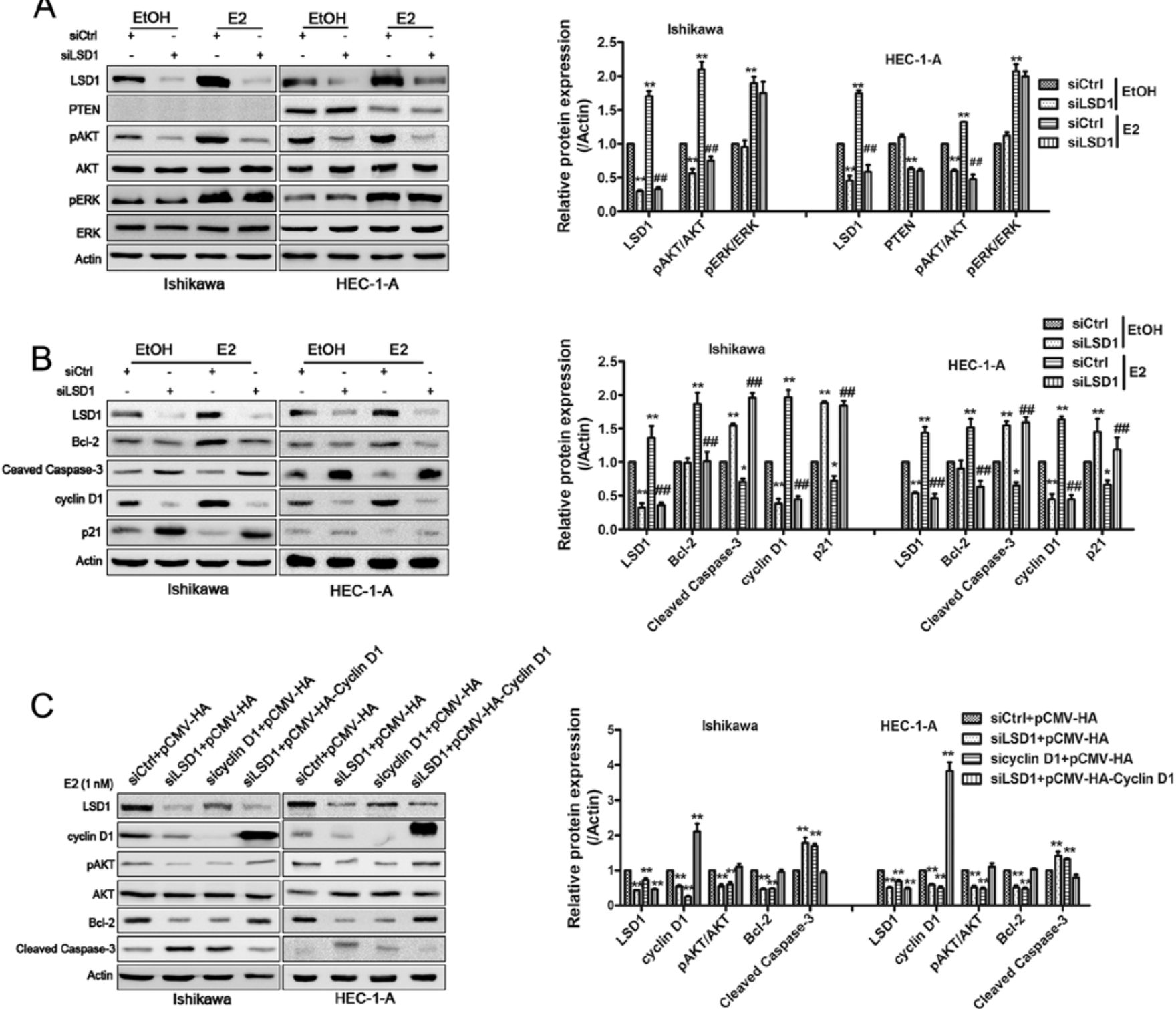

D
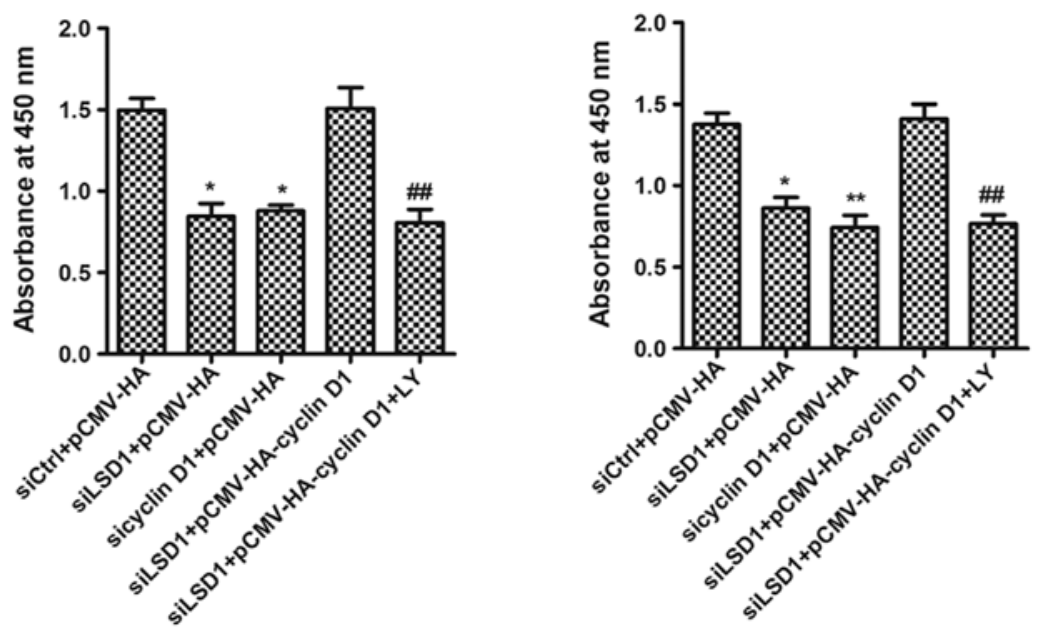

Figure 4. LSD1 establishes a positive-feedback loop in PI3K/AKT signaling. Western blotting was performed to analyze the expression of AKT, p-AKT, ERK, p-ERK, PTEN (A) and cyclin D1, P21, Bcl-2 and cleaved caspase-3 (B). ${ }^{*} \mathrm{P}<0.05,{ }^{* *} \mathrm{P}<0.01$ compared with siControl groups. ${ }^{*} \mathrm{P}<0.05$, ${ }^{\# \#} \mathrm{P}<0.01$ compared with the siControl groups treated with E2. (C) Plasmid encoding cyclin D1 to LSD1-knockdown cells rescued the inhibitory effects in pAKT expression and changes of cyclin D1, Bcl-2 and cleaved caspase-3. ${ }^{*} \mathrm{P}<0.05,{ }^{* *} \mathrm{P}<0.01$ compared with control groups. (D) CCK-8 assays were conducted to quantify cell viability for relevant treated Ishikawa and HEC-1-A cells. ${ }^{*} \mathrm{P}<0.05,{ }^{* *} \mathrm{P}<0.01$ compared with siControl+pCMV-HA groups. ${ }^{*} \mathrm{P}<0.05,{ }^{\# \#} \mathrm{P}<0.01$ compared with the siLSD1+pCMV-HA-cyclin D1 groups. 
E

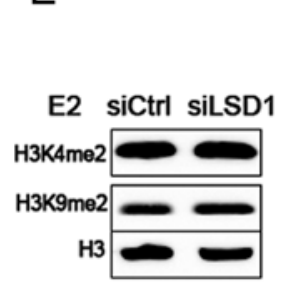

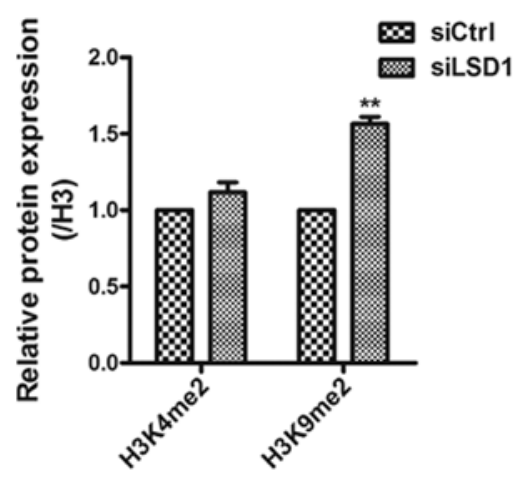

$\mathrm{F}$

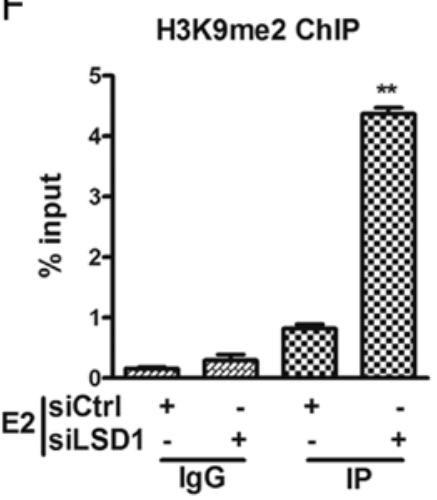

Figure 4. Continued. (E) Total H3K4me2 and H3K9me2 levels were assessed by western blotting after knockdown of LSD1 in E2 treated HEC-1-A cells. ${ }_{* *} \mathrm{P}<0.01$ compared with control groups. (F) ChIP analysis using an H3K9me2 antibody showed that the knockdown of LSD1 induced accumulation of $\mathrm{H} 3 \mathrm{~K} 9 \mathrm{me} 2$ at the promoter region of the cyclin $\mathrm{D} 1 . \mathrm{IgG}$ is used as a negative control. ${ }^{* *} \mathrm{P}<0.01$ compared with control groups.

A
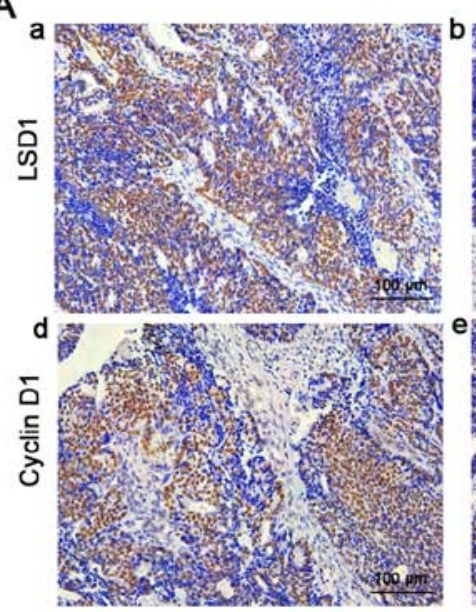
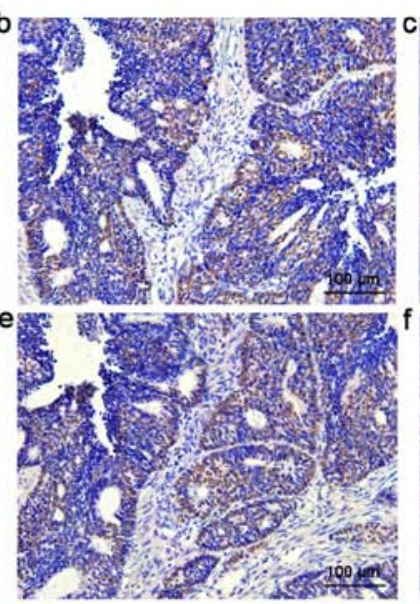

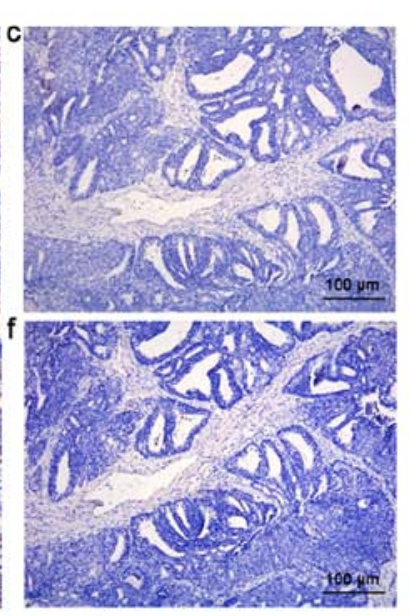

B

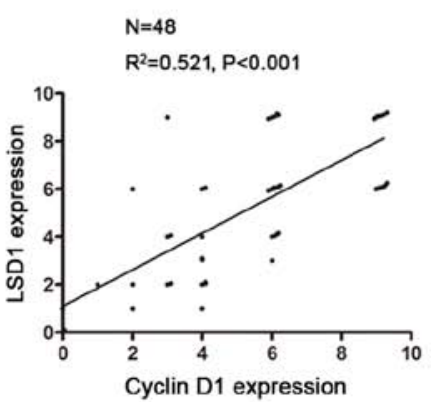

Figure 5. The expression levels of LSD1 is positively associated with cyclin D1 in endometrial cancer tissues. (A) Immunohistochemistry results showing the expression level of LSD1 and cyclin D1 at the same location in endometrial cancer tissues. (a) and (d) were from case 1, (b) and (e) from case 2, (c) and (f) from case 3. Original magnification, $x 200$. (B) The expression of LSD1 positively correlated with the cyclin $D 1$ level $\left(R^{2}=0.521, P<0.001\right)$.

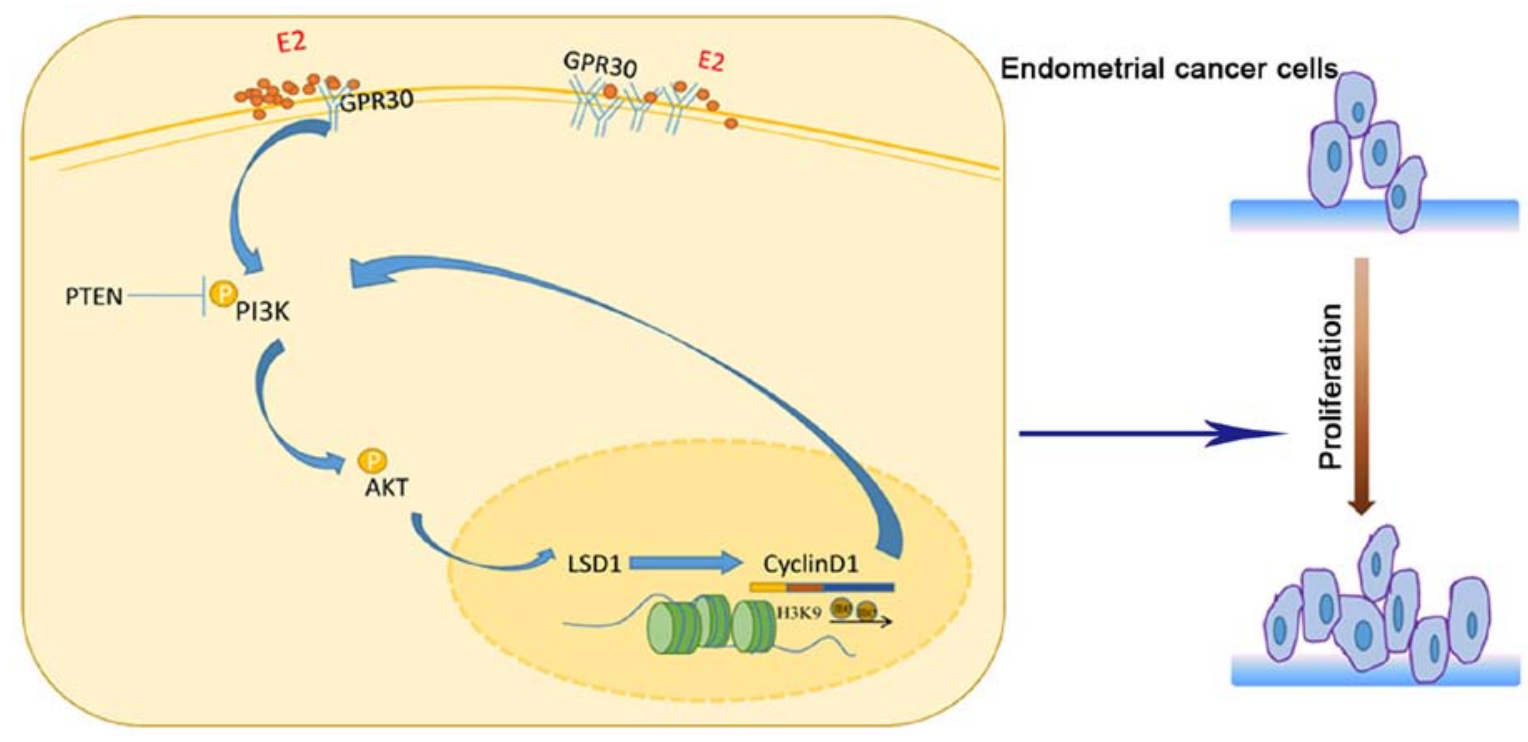

Figure 6. Schematic representation of the pathways required for LSD1 to function in estrogen-induced endometrial cancer cell growth. In different stages of EEC initiation and development, estradiol may induce LSD1 in a GPR30/PI3K/AKT-dependent manner. Elevated LSD1 levels contribute to increased cyclin D1 expression by di-demethylating $\mathrm{H} 3 \mathrm{~K} 9 \mathrm{me} 2$ at its promoter domain, subsequently activating the PI3K/AKT signaling pathway by feedback and eventually resulting in ECCs growth. 
but the underlying mechanisms have yet to be elucidated. In this study, we investigated how LSD1 functions in estrogeninduced endometrial cancer cells.

As an estrogen-related carcinoma, type I endometrial cancer occurs and evolves under continuous estrogen stimulation (4). Mechanistically, estrogen activates estrogen receptors through a genomic pattern by nuclear receptors $(\mathrm{ER} \alpha / \mathrm{ER} \beta)$ and a non-genomic pattern by transmembrane ER (GPR30) (33). Pollock et al (24) found that estrogen signaling increases LSD1 level in the EREs of pS2 and PR genes and inhibiting LSD1 activity attenuated E2 signaling in breast cancer. In this study, we showed that $\beta$-estradiol induced the upregulation of LSD1 in a dose- and time-dependent manner. The GPR30/PI3K/AKT pathway leads to cellular growth in ECCs $(34,35)$, and estrogen stimulation upregulated GPR30/ PI3K/AKT signaling (36), our results similarly confirmed this finding. Shao et al (28) reported that inactivating the PI3K/AKT pathway but not the ERK pathway could block EGF-induced expression of LSD1 in ovarian cancer cells. When GPR30 is knocked down or PI3K/AKT is inactivated by LY294002, LSD1 expression previously activated by estrogen disappeared, which indicated that GPR30/PI3K/ AKT signaling is a determinant for estrogen-induced LSD1 elevation.

LSD1 has been implicated as an oncogene in several types of cancer and tracks cellular growth pathways $(37,38)$. We first investigated the biological behavior of LSD1 in ECCs. Our results demonstrated that LSD1 silencing inhibited cellular proliferation, enhanced cell cycle G1/S arrest and induced apoptosis under both EtOH and E2 treatment. This evidence suggests that LSD1 acts as a tumor promoter in endometrial cancer that promotes tumor proliferation by inducing various aggressive physiological behaviors. Lin et al (39) recently found that LSD1 can be recruited by Snail to the promoter of PTEN, where it demethylates histone H3 lysine 4 and contributes to transcriptional repression. Yokoyama et al also reported that the LSD1-CoREST complex can be recruited by nuclear receptor TLX to the promoter of PTEN to downregulate PTEN expression $(25,26)$. Plenty of research work has suggested that the most frequently altered signaling cascade in EEC is the PI3K/AKT pathway, which is dysregulated by oncogenic mutations and PTEN dysfunction, resulting in uncontrolled cell proliferation (40). As a tumor suppressor gene, PTEN activity can be reduced by subcutaneous estradiol in vivo and estradiol treatment in vitro $(41,42)$. This prompted us to examine the role of LSD1 in estrogen-driven cell growth and influence on PI3K/AKT signaling pathway. Intriguingly, we found that knocking down LSD1 decreased estrogen-induced pAKT and altered the expression of certain downstream genes related to the cell cycle (cyclin D1 and P21) and cell apoptosis (Bcl-2, cleaved caspase-3), but did not upregulate PTEN expression in either PTEN-mutated Ishikawa or wtPTEN HEC-1-A cells as expected. This result indicated that LSD1 plays a critical role in the estrogenregulated $\mathrm{PI} 3 \mathrm{~K} / \mathrm{AKT}$ pathway but without causing significant changes in PTEN expression in EEC.

As a marker of poor prognosis and an important promoter of the cell cycle, cyclin D1 is overexpressed in various cancer types, and acts as a sensor in response to a number of extracellular stimuli (43-45). Our previous study showed that estrogen enhances ECC proliferation via promotion of cyclin D1 expression (36). Surprisingly, the depletion of LSD1 tremendously suppressed estrogen-induced cyclin D1 levels, which lead us to hypothesize that LSD1 carcinogenesis is associated with cyclin D1 variation. Zhong et al reported that both cyclin D1 and cyclin D1-CDK4/6 kinase activity can decrease cell motility and reduce invasion and migration in breast cancer cells (46). Moreover, cyclin D1 was demonstrated to regulate DICER, a critical component in microRNA biogenesis and mature microRNA production, and subsequent miRNA expression (47). Recently, Chen et al found that cyclin D1 interference inhibits proliferation, invasion and migration by reducing PI3K/AKT levels in colon cancer cells (31). We speculated that cyclin D1 also plays an important role in LSD1-regulated estrogen-induced endometrial cancer cell proliferation. Our study confirmed this role, knockdown of cyclin D1 reduced LSD1 expression, inhibited p-AKT and its downstream gene Bcl-2 while upregulating cleaved caspase-3, consistent with the siLSD1 groups. Overexpression of cyclin D1 reversed the effects of the PI3K/AKT pathway in LSD1 silencing Ishikawa and HEC-1-A cells. Additional PI3K/AKT inhibition led to the blocking of proliferation, which indicated the existence of a LSD1/cyclin D1/PI3K/AKT feedback loop in EEC. By ChIP assay, we showed that LSD1 removes transcriptionally repressive di-methyl marks from H3K9 in the cyclin D1 promoter region. The results presented here demonstrate that LSD1 induces EEC growth through downregulating the expression of cyclin D1 via demethylating H3K9me2, which can be reversed when cyclin D1 is simultaneously upregulated. Correlation analysis by immunohistochemistry also verified the positive correlation between LSD1 and cyclin D1 in endometrial cancer tissues.

In conclusion, our findings present the first evidence that LSD1 plays an essential role in estrogen-regulated type I endometrial cancer and establishes a crucial LSD1/cyclin D1/PI3K/ AKT feedback loop in endometrial cancer cells (Fig. 6), which supplements the epigenetic characteristics of endometrial cancer. As a novel agent in endometrial cancer, LSD1 will be a potent therapeutic target in the future. In recent years, the enzymatic activity of LSD1 and its overexpression in many human malignancies has become a significant focus for the development of pharmacologic inhibitors (48). Based on these results, further studies are underway to elucidate the molecular mechanisms of LSD1 and to seek effective LSD1 inhibitors in order to better understand the molecular basis of endometrial cancer.

\section{Acknowledgements}

This study was supported by the National Key Clinical Specialist Construction Programs of China, the National Natural Science Foundation of China (NSFC nos. 81201541, 81502230 and 81402134) and the Shanghai Pu Jiang Talent Program (12PJD002).

\section{References}

1. Siegel RL, Miller KD and Jemal A: Cancer statistics, 2016. CA Cancer J Clin 66: 7-30, 2016.

2. Deligdisch L and Holinka CF: Endometrial carcinoma: Two diseases? Cancer Detect Prev 10: 237-246, 1987. 
3. Makker A and Goel MM: Tumor progression, metastasis, and modulators of epithelial-mesenchymal transition in endometrioid endometrial carcinoma: An update. Endocr Relat Cancer 23: R85-R111, 2016.

4. Gibson WJ, Hoivik EA, Halle MK, Taylor-Weiner A, Cherniack AD, Berg A, Holst F, Zack TI, Werner HM, Staby KM, et al: The genomic landscape and evolution of endometrial carcinoma progression and abdominopelvic metastasis. Nat Genet 48: 848-855, 2016

5. Westin SN, Ju Z, Broaddus RR, Krakstad C, Li J, Pal N, Lu KH, Coleman RL, Hennessy BT, Klempner SJ, et al: PTEN loss is a context-dependent outcome determinant in obese and non-obese endometrioid endometrial cancer patients. Mol Oncol 9: $1694-1703,2015$

6. Slomovitz BM and Coleman RL: The PI3K/AKT/mTOR pathway as a therapeutic target in endometrial cancer. Clin Cancer Res 18 : 5856-5864, 2012.

7. Li Y, Jia Y, Che Q, Zhou Q, Wang K and Wan XP: AMF/ PGI-mediated tumorigenesis through MAPK-ERK signaling in endometrial carcinoma. Oncotarget 6: 26373-26387, 2015.

8. Wang Y, van der Zee M, Fodde R and Blok LJ: Wnt/ $\beta$-catenin and sex hormone signaling in endometrial homeostasis and cancer. Oncotarget 1: 674-684, 2010.

9. Strahl BD and Allis CD: The language of covalent histone modifications. Nature 403: 41-45, 2000

10. Elsheikh SE, Green AR, Rakha EA, Powe DG, Ahmed RA, Collins HM, Soria D, Garibaldi JM, Paish CE, Ammar AA, et al: Global histone modifications in breast cancer correlate with tumor phenotypes, prognostic factors, and patient outcome. Cancer Res 69: 3802-3809, 2009.

11. Shi Y, Lan F, Matson C, Mulligan P, Whetstine JR, Cole PA, Casero RA and Shi Y: Histone demethylation mediated by the nuclear amine oxidase homolog LSD1. Cell 119: 941-953, 2004.

12. Zuchegna C, Aceto F, Bertoni A, Romano A, Perillo B, Laccetti P, Gottesman ME, Avvedimento EV and Porcellini A: Mechanism of retinoic acid-induced transcription: Histone code, DNA oxidation and formation of chromatin loops. Nucleic Acids Res 42: 11040-11055, 2014

13. Lim S, Janzer A, Becker A, Zimmer A, Schüle R, Buettner R and Kirfel J: Lysine-specific demethylase 1 (LSD1) is highly expressed in ER-negative breast cancers and a biomarker predicting aggressive biology. Carcinogenesis 31: 512-520, 2010.

14. Nagasawa S, Sedukhina AS, Nakagawa Y, Maeda I, Kubota M, Ohnuma S, Tsugawa K, Ohta T, Roche-Molina M, Bernal JA, et al: LSD1 overexpression is associated with poor prognosis in basal-like breast cancer, and sensitivity to PARP inhibition. PLoS One 10: e0118002, 2015.

15. Kashyap V, Ahmad S, Nilsson EM, Helczynski L, Kenna S, Persson JL, Gudas LJ and Mongan NP: The lysine specific demethylase-1 (LSD1/KDM1A) regulates VEGF-A expression in prostate cancer. Mol Oncol 7: 555-566, 2013.

16. Qin Y, Zhu W, Xu W, Zhang B, Shi S, Ji S, Liu J, Long J, Liu C, Liu L, et al: LSD1 sustains pancreatic cancer growth via maintaining HIF1 $\alpha$-dependent glycolytic process. Cancer Lett 347: 225-232, 2014

17. Chen C, Ge J, Lu Q, Ping G, Yang C and Fang X: Expression of lysine-specific demethylase 1 in human epithelial ovarian cancer. J Ovarian Res 8: 28, 2015.

18. Mohammad HP, Smitheman KN, Kamat CD, Soong D, Federowicz KE, Van Aller GS, Schneck JL, Carson JD, Liu Y, Butticello M, et al: A DNA hypomethylation signature predicts antitumor activity of LSD1 inhibitors in SCLC. Cancer Cell 28 : 57-69, 2015.

19. Fiskus W, Sharma S, Shah B, Portier BP, Devaraj SG, Liu K, Iyer SP, Bearss D and Bhalla KN: Highly effective combination of LSD1 (KDM1A) antagonist and pan-histone deacetylase inhibitor against human AML cells. Leukemia 28: 2155-2164, 2014.

20. Theisen ER, Gajiwala S, Bearss J, Sorna V, Sharma S and Janat-Amsbury M: Reversible inhibition of lysine specific demethylase 1 is a novel anti-tumor strategy for poorly differentiated endometrial carcinoma. BMC Cancer 14: 752, 2014.

21. Liu YD, Dai M, Yang SS, Xiao M, Meng FL and Chen XW: Overexpression of lysine-specific demethylase 1 is associated with tumor progression and unfavorable prognosis in Chinese patients with endometrioid endometrial adenocarcinoma. Int J Gynecol Cancer.25: 1453-1460, 2015.

22. Cai C, He HH, Gao S, Chen S, Yu Z, Gao Y, Chen S, Chen MW, Zhang J, Ahmed M, et al: Lysine-specific demethylase 1 has dual functions as a major regulator of androgen receptor transcriptional activity. Cell Rep 9: 1618-1627, 2014
23. Bennesch MA, Segala G, Wider D and Picard D: LSD1 engages a corepressor complex for the activation of the estrogen receptor $\alpha$ by estrogen and cAMP. Nucleic Acids Res 44: 8655-8670, 2016.

24. Pollock JA, Larrea MD, Jasper JS, McDonnell DP and McCafferty DG: Lysine-specific histone demethylase 1 inhibitors control breast cancer proliferation in ER $\alpha$-dependent and -independent manners. ACS Chem Biol 7: 1221-1231, 2012

25. Sun G, Alzayady K, Stewart R, Ye P, Yang S, Li W and Shi Y: Histone demethylase LSD1 regulates neural stem cell proliferation. Mol Cell Biol 30: 1997-2005, 2010.

26. Yokoyama A, Takezawa S, Schüle R, Kitagawa H and Kato S: Transrepressive function of TLX requires the histone demethylase LSD1. Mol Cell Biol 28: 3995-4003, 2008.

27. Chen J, Bai M, Ning C, Xie B, Zhang J, Liao H, Xiong J, Tao X, Yan D, Xi X, et al: Gankyrin facilitates follicle-stimulating hormone-driven ovarian cancer cell proliferation through the PI3K/AKT/HIF-1 $\alpha /$ cyclin D1 pathway. Oncogene 35: 2506-2517, 2016.

28. Shao G, Wang J, Li Y, Liu X, Xie X, Wan X, Yan M, Jin J, Lin Q, Zhu $\mathrm{H}$, et al: Lysine-specific demethylase 1 mediates epidermal growth factor signaling to promote cell migration in ovarian cancer cells. Sci Rep 5: 15344, 2015.

29. Liu Y, Zhang J, Qian W, Dong Y, Yang Y, Liu Z, Feng Y, Ma D, Zhang $\mathrm{Z}$ and $\mathrm{Wu} \mathrm{S}$ : Gankyrin is frequently overexpressed in cervical high grade disease and is associated with cervical carcinogenesis and metastasis. PLoS One 9: e95043, 2014.

30. Jin X, Gossett DR, Wang S, Yang D, Cao Y, Chen J, Guo R, Reynolds RK and Lin J: Inhibition of AKT survival pathway by a small molecule inhibitor in human endometrial cancer cells. $\mathrm{Br}$ J Cancer 91: 1808-1812, 2004.

31. Chen Y, Jiang J, Zhao M, Luo X, Liang Z, Zhen Y, Fu Q, Deng X, Lin X, Li L, et al: microRNA-374a suppresses colon cancer progression by directly reducing CCND1 to inactivate the PI3K/ AKT pathway. Oncotarget 7: 41306-41319, 2016.

32. Torres-Padilla ME, Parfitt DE, Kouzarides T and ZernickaGoetz M: Histone arginine methylation regulates pluripotency in the early mouse embryo. Nature 445: 214-218, 2007.

33. Prossnitz ER, Arterburn JB, Smith HO, Oprea TI, Sklar LA and Hathaway HJ: Estrogen signaling through the transmembrane $\mathrm{G}$ protein-coupled receptor GPR30. Annu Rev Physiol 70: 165-190, 2008.

34. Ge X, Guo R, Qiao Y, Zhang Y, Lei J, Wang X, Li L and Hu D: The G protein-coupled receptor GPR30 mediates the nontranscriptional effect of estrogen on the activation of PI3K/Akt pathway in endometrial cancer cells. Int J Gynecol Cancer 23: 52-59, 2013.

35. Wei Y, Zhang Z, Liao H, Wu L, Wu X, Zhou D, Xi X, Zhu Y and Feng Y: Nuclear estrogen receptor-mediated Notch signaling and GPR30-mediated PI3K/AKT signaling in the regulation of endometrial cancer cell proliferation. Oncol Rep 27: 504-510, 2012.

36. Zhang J, Yang Y, Zhang Z, He Y, Liu Z, Yu Y, Wu S, Cai B and Feng $Y$ : Gankyrin plays an essential role in estrogen-driven and GPR30-mediated endometrial carcinoma cell proliferation via the PTEN/PI3K/AKT signaling pathway. Cancer Lett 339: 279-287, 2013

37. Wang Y, Zhu Y, Wang Q, Hu H, Li Z, Wang D, Zhang W, Qi B, Ye J, Wu H, et al: The histone demethylase LSD1 is a novel oncogene and therapeutic target in oral cancer. Cancer Lett 374: $12-21,2016$

38. Thambyrajah R, Mazan M, Patel R, Moignard V, Stefanska M, Marinopoulou E, Li Y, Lancrin C, Clapes T, Möröy T, et al: GFI1 proteins orchestrate the emergence of haematopoietic stem cells through recruitment of LSD1. Nat Cell Biol 18: 21-32, 2016.

39. Lin Y, Kang T and Zhou BP: Doxorubicin enhances Snail/LSD1mediated PTEN suppression in a PARP1-dependent manner. Cell Cycle 13: 1708-1716, 2014.

40. Hecht JL and Mutter GL: Molecular and pathologic aspects of endometrial carcinogenesis. J Clin Oncol 24: 4783-4791, 2006.

41. Ono H, Katagiri H, Funaki M, Anai M, Inukai K, Fukushima Y, Sakoda H, Ogihara T, Onishi Y, Fujishiro M, et al: Regulation of phosphoinositide metabolism, Akt phosphorylation, and glucose transport by PTEN (phosphatase and tensin homolog deleted on chromosome 10) in 3T3-L1 adipocytes. Mol Endocrinol 15: $1411-1422,2001$

42. Yang CH, Almomen A, Wee YS, Jarboe EA, Peterson CM and Janát-Amsbury MM: An estrogen-induced endometrial hyperplasia mouse model recapitulating human disease progression and genetic aberrations. Cancer Med 4: 1039-1050, 2015. 
43. Seiler R, Thalmann GN, Rotzer D, Perren A and Fleischmann A CCND1/CyclinD1 status in metastasizing bladder cancer: a prognosticator and predictor of chemotherapeutic response. Modern Pathol 27: 87-95, 2014.

44. Dreyer JH, Hauck F, Barros MH and Niedobitek G: pRb and cyclinD1 complement p16 as immunohistochemical surrogate markers of HPV infection in head and neck cancer. Appl Immunohistochem Mol Morphol: Dec 9, 2015 (Epub ahead of print).

45. Umekita Y, Ohi Y, Sagara Y and Yoshida H: Overexpression of cyclinD1 predicts for poor prognosis in estrogen receptornegative breast cancer patients. Int J Cancer 98: 415-418, 2002.
46. Zhong Z, Yeow WS, Zou C, Wassell R, Wang C, Pestell RG, Quong JN and Quong AA: Cyclin D1/cyclin-dependent kinase 4 interacts with filamin A and affects the migration and invasion potential of breast cancer cells. Cancer Res 70: 2105-2114, 2010.

47. Sun X, Tang SC, Xu C, Wang C, Qin S, Du N, Liu J, Zhang Y, Li X, Luo G, et al: DICER1 regulated let-7 expression levels in p53-induced cancer repression requires cyclin D1. J Cell Mol Med 19: 1357-1365, 2015.

48. Maiques-Diaz A and Somervaille TC: LSD1: Biologic roles and therapeutic targeting. Epigenomics 8: 1103-1116, 2016. 